\title{
Analysis of a gold solidus of roman emperor Valentinian I
}

\author{
J. Cruz $* * *, * * *$, V. Corregidor**,***, L.C. Alves*****, P.A. Carvalho**** and M. Fonseca******* \\ *Departamento de Física, Faculdade de Ciências e Tecnologia, Universidade Nova de Lisboa, 2829-516 \\ Caparica, Portugal \\ **Campus Tecnológico e Nuclear, IST/ITN, Instituto Superior Técnico, Universidade Técnica de Lisboa \\ Estrada Nacional 10, 2686-953 Sacavém, Portugal \\ ***Centro de Física Nuclear da Universidade de Lisboa, Av. Prof. Gama Pinto, 1649-003 Lisboa, Portugal \\ ****ICEMS, Instituto Superior Técnico, Universidade de Lisboa, Av. Rovisco Pais, 1049-001 Lisboa, Portugal
}

A gold solidus of Valentinian I, Emperor of Rome (A.D. 364-375) shown in Figure 1, and belonging to a private collection, was subjected to material and stylistic analysis, in order to ascertain about its authenticity. Due to the rarity of such a coin, only non-destructive analytical techniques were used, namely Scanning Electron Microscopy (SEM), Particle Induced X-ray Emission (PIXE), electrical resistivity and optical microscopy.

Examination by SEM revealed that, in common with coins minted by this emperor, the solidus was die-struck as evidenced by the surface flow lines indicating metal movement under the dies (Figure 2). Wear traces presented an unorganized pattern. The coin was also examined for signs of stress-corrosion cracking but no evidence of this were found. The coin also shows traces of what appear to be soil residues; small quantities of these residues can also be seen in porosities in the coin face (arrow in Figure 3).

Analysis by PIXE showed that the coin was made from an alloy of gold (97.9\%), silver (2.0\%) and copper $(0.1 \%)$ (Figure 4$)$. The high gold content is likely to be overestimated due to surface depletion of the silver and particularly the copper, which is caused by slight dissolution of these more reactive metals in the burial environment. Nevertheless, this effect is usually small and in agreement with other solidus from Valentiniano I [1]. Also, the high gold content may lie behind the lack of stress-corrosion cracking.

The presence of platinum group element (PGE) inclusions is, in some cases, indicative of alluvial gold provenience. Both, optical microscopy and PIXE, were used to detect them but it was not possible to identify their presence. Typically, the concentration of these elements is in the order of ppm, although for this specific period different values have been reported [1]. Considering the experimental conditions used ( $2 \mathrm{MeV}$ accelerated proton beam and a $50 \mu \mathrm{m}$ Mylar foil in front of the X-ray detector) the limit of detection of the PIXE technique is close to the expected trace concentration. More energetic proton beam $(>3 \mathrm{MeV})$ or the use of specific filter for the X-ray signal in the low energy region, i.e. Zinc foil $75 \mu \mathrm{m}$ thick, are the future experiments to be carried out in order to detect the presence of such characteristics PGE elements.

In order to understand the presumable surface gold enrichment, electrical conductivity measurements were used. The values obtained (1.50-1.56) $\times 10^{17} \mathrm{~S} / \mathrm{m}$ show a lower conductivity as compared with the reference value for a $97 \% \mathrm{Au}, 3 \% \mathrm{Ag}$ alloy $\left(3.54 \times 10^{17} \mathrm{~S} / \mathrm{m}\right)$ [2], indicating that indeed the coin bulk has a lower gold content.

As for the stylistic analysis, there is no sound agreement about the coin authenticity, but the tendency is to consider it a good one. The compositional and structural characterization of cultural heritage artefacts usually limit the number of available techniques to those considered as non-destructive and non-invasive, such the one presented in this work. This restriction also constricts and difficult the desired straight conclusions but, on the other hand, increase the multidisciplinary of the work, applying techniques usually dedicated to the material science characterization to cultural heritage. 


\section{References}

1. Morrison C., Comptes-rendus des séances de l'Académie des Inscriptions et Belles-Lettres, 126e:203, 1982.

2. Ho C.Y. et al., J. Phys. Chem. Ref. Data, 12:183, 1983.

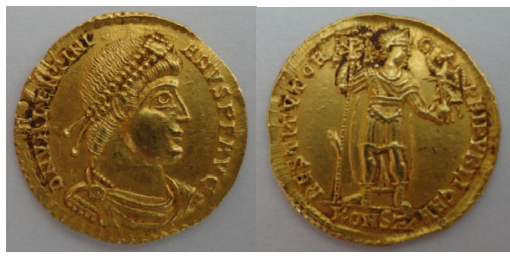

Figure 1. Image of analysed coin.

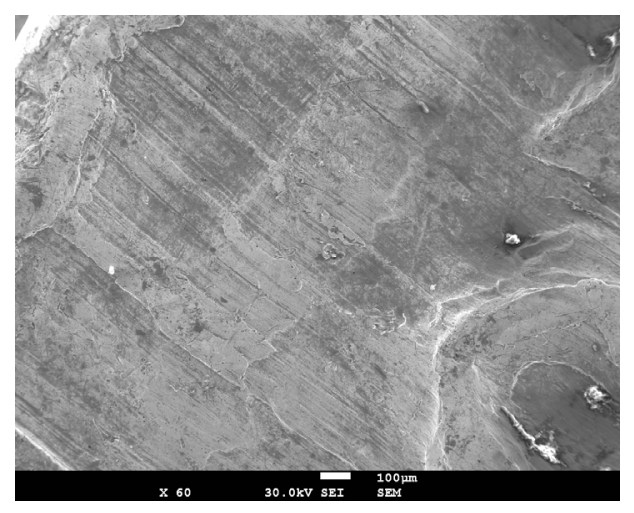

Figure 2. SEM image of the gold solidus showing striations due to die striking.

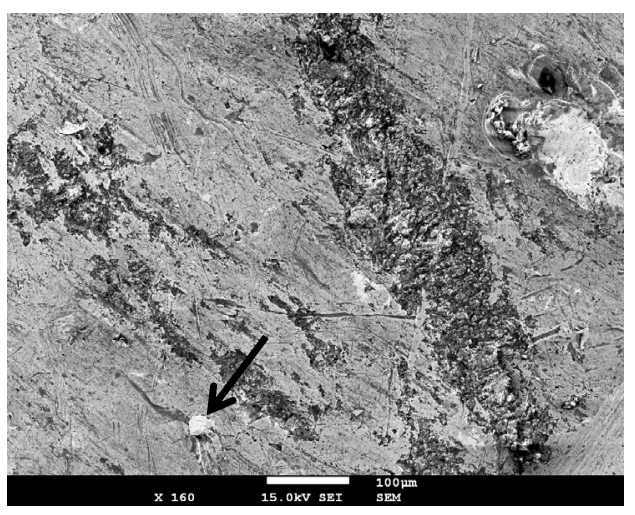

Figure 3. SEM image showing siliceous material in some of the cavities.

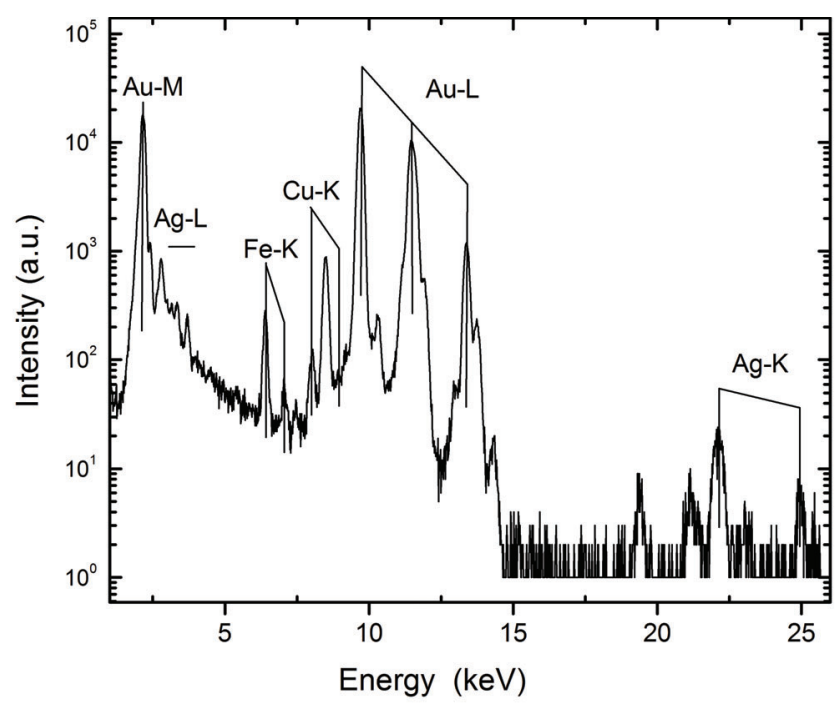

Figure 4. PIXE spectrum recorded using a $2 \mathrm{MeV}$ proton beam. Scanned area: 1060x1060 $\mu \mathrm{m}^{2}$.

V. Corregidor acknowledges the funding support from the FCT-Ciência program. Financial support was also received through the PEST-OE/CTM-UI0084/2011 and PEST-OE/FIS/UI0275/2011 grants. 